\title{
ASPEK KONSTRUKTIVIS DALAM SENGKETA WILAYAH KASHMIR ANTARA INDIA DAN PAKISTAN
}

\author{
Agung Y. Nugroho \\ Universitas 17 Agustus 1945 Jakarta \\ aijn_agung@yahoo.com
}

\begin{abstract}
Abstrack
Kashmir region is a complex area. Kashmir territorial dispute is caused by the impact on the political interests of both countries and through a unilateral claim of India and Pakistan. Issue a struggle power between India and Pakistan which the two countries mutually detterence launched through testing their nuclear weapons increasingly sharpening conflict between the two countries. The case of a prolonged struggle for Kashmir region forced the United Nations to find a solution as a step to solve the problem in Kashmir. The UN Security Council sends to India and Pakistan by bringing a proposal that suggested the two countries demilitarize over Kashmir to ensure that the polls are offered not take sides with one country. However, the proposal was rejected by India. India considered that the Kashmir issue is a bilateral issue with Pakistan. Resolution will be undertaken by the UN is always doomed to failure. This will be appointed by the author to see the extent of the territorial dispute escalating conflict.
\end{abstract}

Keywords: Kashmir territorial, Billateral Conflict, India and Pakistan, struggle power, United Nations

\section{Pendahuluan}

\section{Latar Belakang Masalah}

Wilayah Kashmir adalah suatu wilayah di Asia Selatan yang struktur geografisnya dialiri oleh sungai-sungai yang membelah Asia Selatan dan membuatnya sangat subur dan sangat menarik minat negara-negara disekitarnya untuk menguasainya. Sengketa yang terjadi di wilayah Kashmir ini berpengaruh besar di kawasan Asia Selatan, karena sengketa tersebut melibatkan dua negara besar yaitu India dan Pakistan. Perseteruan dua negara untuk mendapatkan wilayah Kashmir ini masih terus berlanjut dan menarik perhatian dunia Internasional sebagai upaya untuk penyelesaian sengketa tersebut. Konflik ini bermula dari akibat disintegrasi India yang melahirkan negara Pakistan. Apabila 
pemeluk agama Hindu India dimasa lalu tidak bersikap diskriminatif dan menerima keberadaan pemeluk agama Islam di India mungkin tidak akan ada disintegrasi India yang kemudian menimbulkan perebutan wilayah Kashmir. ${ }^{1}$ Ditambah lagi masalah adu kekuatan antara India dan Pakistan dimana kedua negara saling melancarkan detterence melalui uji coba senjata nuklir mereka semakin meruncingnya konflik antara kedua negara. Masalah demi masalah terus bermunculan semakin memperkeruh konflik yang terjadi diantara kedua negara. Beberapa diantaranya, tentara India diberikan imunitas untuk tidak dikenai hukuman terhadap tindakan kekerasan yang mereka lakukan melalui sebuah Akta Angkatan Bersenjata Jammu dan Kashmir. ${ }^{2}$

Wilayah Kashmir masyarakatnya beragama Islam, akan menjadi bagian integral dari Pakistan. India menganggap bahwa konflik Kashmir bukanlah masalah agama. Atas dasar tersebut India menunjukan bahwa wilayah Kashmir di masa lalu yang sebagian besar penduduknya beragama Islam dan pemerintahnya beragama Hindu dapat hidup berdampingan secara damai. Pemeluk Islam di Kashmir menganut aliran sufisme yang merupakan ajaran yang lebih mengutamakan spiritual. Pemeluk ajaran ini dapat seiring sejalan dengan dengan spiritualisme Hindu. Kerajaan Kashmir yang mayoritas beragama Islam dan Jатmи yang mayoritas beragama Hindu, berada di bawah kerajaan Hindu merupakan wilayah yang aman, sejahtera, dan warganya dapat hidup rukun serta saling menghormati. Akan tetapi anggapan dari india tersebut dianggap oleh Pakistan dimana India sengaja memutar-balikkan fakta sebagai dasar untuk untuk menguasai wilayah Kashmir. Menurut Pakistan, penduduk Kashmir yang mayoritas beragama Islam sudah sepantasnya menjadi bagian dari Pakistan.

India masuk ke Kashmir secara paksa tanggal 26 Oktober 1947, India mengaku menandatangani perjanjian kerjasama dengan Maharaja Kashmir. Dokumen perjanjian itu berisi permintaan Maharaja kepada India supaya

\footnotetext{
${ }^{1}$ Icha. Implikasi Konflik Kashmir Terhadap Regional Security Kawasan Asia Selatan. http://chaegyoung.wordpress.com/2009/10/25/ diakses tanggal 17 Januari 2014.

${ }^{2}$ Ibid.
} 
mengirimkan tentaranya ke Kashmir untuk menumpas pemberontakan. Dokumen kontroversial inilah yang menjadi alasan India menduduki Kashmir. Pakistan dan orang-orang Kashmir memprotes kedatangan tentara India itu. India Mengklaim seluruh negara Jammu dan Kashmir dan pada tahun 2010, India memerintah sekitar $43 \%$ dari wilayah Kashmir, termasuk sebagian besar dari Jammu, Lembah Kashmir, Ladakh, dan Gletser Siachen. Klaim India ditentang oleh Pakistan, yang memerintah sekitar 37\% dari wilayah Kasmir, yaitu Azad Kashmir dan bagian utara dari Gilgit Baltistan. ${ }^{3}$

Kasus perebutan wilayah Kashmir yang berkepanjangan memaksa PBB untuk mencari solusi sebagai langkah untuk menyelesaikan masalah di Kashmir. PBB mengirimkan Dewan Keamanannya ke India dan Pakistan dengan membawa sebuah proposal yang menyarankan agar kedua negara melakukan demiliterisasi atas Kashmir untuk memastikan bahwa proses jajak pendapat yang ditawarkan tidak memihak salah satu negara. Akan tetapi proposal tersebut ditolak oleh India. India beranggapan bahwa masalah Kashmir merupakan masalah bilateral dengan Pakistan. ${ }^{4}$

\section{Rumusan masalah}

Berdasarkan atas latar belakang tersebut di atas, penulis memfokuskan penelitian ini menjadi dua rumusan masalah yaitu;

1. Apa aspek-aspek konstruktivis dalam sengketa wilayah Kashmir antara India dan Pakistan dilihat dari perspektif India sebagai negara yang selalu menolak resolusi yang ditawarkan oleh PBB.

2. Bagaimana penyelesaian sengketa perbatasan wilayah Kashmir menurut Hukum Internasional?

\footnotetext{
${ }^{3}$ Choudhury, Salah Uddin Shoaib (8 Oktober 2010). "Pakistani rogue policy on Kashmir". Sri Lanka Guardian. Diakses 17 Januari 2014.

${ }^{4}$ Uppsala Conflict Data Program Conflict Encyclopedia, Conflict Summary, Conflict name: India: Kashmir, "Roots of Conflict and the emergence of Kashmir Insurgents", http://www.ucdp.uu.se/gpdatabase/gpcountry.php?id=74\&regionSelect=6Central_and_Southern_Asia\# diakses tanggal 17 Januari 2014.
} 


\section{Pembahasan}

Untuk melihat perspektif India dalam sengketa di Kashmir ini, penulis akan menggunakan teori konstruktivis. Menurut Christian Reus-Smit, ${ }^{5}$ konstruktivisme sebagai pendekatan yang memiliki konsepsi yang lebih berguna dalam menganalisis politik dan hukum internasional. Pandangan konstruktivis ini digunakan untuk memahami hubungan antara politik internasional dan hukum internasional. Politik internasional ini merupakan bentuk tindakan sosial, sementara hukum internasional merupakan pusat struktur-struktur normatif yang membentuk politik dan tindakan negara yang sah. Struktur tersebut sebagai pembentuk perilaku aktor sosial dan politik. Di mana kepentingan (sebagai dasar bagi tindakan atau perilaku politik) bukan menggambarkan rangkaian preferensi yang baku, yang telah dimiliki aktor-aktor politik melainkan sebagai produk identitas aktor-aktor tersebut. Struktur bersama dengan agen saling menentukan satu sama lain. ${ }^{6}$

Negara dalam hubungan internasional merupakan pelaku utama (aktor), maka yang menjadi perhatian utama hukum internasional adalah hak dan kewajiban serta kepentingan negara. Negara sebagai salah satu subjek hukum internasional, bahkan menjadi subjek hukum internasional yang pertama dan utama serta terpenting (par excellence). Negara menjadi subjek hukum internasional yang pertama-tama, sebab kenyataan menunjukkan bahwa yang pertama-tama yang mengadakan hubungan internasional. Negara sebagai suatu kesatuan politik dalam hukum internasional yang juga sifatnya keterutamaannya maka suatu negara harus memiliki unsur-unsur tertentu berdasarkan hukum internasional. Aturan hukum internasional yang disediakan masyarakat

\footnotetext{
${ }^{5}$ Christian Reus-Smit, 2004. "The Politics of International Law", Cambridge University Press. ${ }^{6}$ Ibid.
} 
internasional dapat dipastikan berupa aturan tingkah laku yang harus ditaati oleh negara apabila mereka saling mengadakan hubungan kerjasama. ${ }^{7}$

Ada empat pertimbangan politik dalam konstruktivis, yang pertama adalah; Idiographic merupakan hal yang berkaitan dengan masalah identitas para aktor (Who am I? Who are we?). Berikutnya adalah Purposive, merupakan pertimbangan akan hal yang diinginkan oleh para aktor (What do I want? What do we want?). Selanjutnya, Etichal. Etichal merupakan hal yang mengenai bagaimana para aktor harus bertindak (How I should act?). Dan yang terakhir adalah Instrumental. Instrumental menjelaskan bagaimana para aktor mendapatkan atau mencapai hal yang diinginkan (How do I get what I want?). ${ }^{8}$

Di sini penulis menganalisa konsep konstruktivis ini dari sudut pandang negara India. Dari segi Idiographic, India menganggap dirinya sebagai komunitas Hindu terbesar didunia dan memiliki dominasi yang kuat atas Kashmir berdasarkan pada sejarah masa lampau bahwa Kashmir merupakan wilayah yang diperintah oleh pemeluk agama Hindu. Begitu pula dengan Idiographic dari Pakistan adalah, Pakistan menganggap bahwa Kashmir merupakan wilayah yang sebagian besar penduduknya beragama Islam dan sudah selayaknya menjadi bagian dari Pakistan yang merupakan negara yang mayoritas Islam. Disini India mengklaim dirinya sebagai hegemon di wilayah Asia Selatan dan untuk menunjukan dominasinya tersebut India menolak campur tangan asing sebagai mediator dalam sengketa Kashmir termasuk dari PBB.

Secara Purposive, India berusaha untuk memperkuat pengaruhnya dikawasan Kashmir serta mempertegas integritas teritorialnya. Serta dengan menguasai Kashmir India mampu untuk melakukan ekspansi yang lebih luas atas wilayahnya dan dapat menekan dan melemahkan basis pertahanan wilayah Pakistan.

\footnotetext{
${ }^{7}$ Mohd. Burhan Tsani, Hukum dan Hubungan Internasional, Penerbit Liberty, Yogyakarta,1990, hlm. 12.

${ }^{8}$ Reus-Smit,Op.Cit.
} 
Dari segi ethical, ada beberapa perjanjian yang mendasari India untuk menguasai Kashmir, yang pertama adalah India menempatkan Treaty of Amritsar 16 Maret 1846, sebagai penyerahan Kashmir dari Inggris kepada masyarakat Hindu, kemudian dalam Article 370 Konstitusi India, tentang hukum yang memberikan otonomi khusus pada Jammu dan Kashmir. Selanjutnya adalah Instrument of Accession (accession treaty) yang ditandatangani tanggal 26 Oktober 1947 oleh Maharaja Singh, dimana Kashmir masuk ke dalam bagian integral India sebagai syarat permohonan bantuan militer dari India.

Berikutnya dari segi Instrumental, tentara India diberikan imunitas untuk tidak dikenakan hukuman atas tindakan kekerasan yang mereka lakukan (special powers) melalui sebuah Akta Angkatan Bersenjata Jammu dan Kashmir. Serta melakukan detterence terhadap Pakistan dengan show of power persenjataan nuklir India. Pemerintah India juga menolak peran PBB sebagai pihak ketiga untuk menyelesaikan sengketa dengan alasan bahwa Kashmir adalah urusan bilateral India dan Pakistan.

Uraian selanjutnya adalah untuk menjawab rumusan masalah tentang penyelesaian sengketa wilayah Kashmir Menurut Hukum Internasional. Sengketa wilayah kashmir adalah sengketa internasional. Sengketa internasional adalah sengketa yang melibatkan antara dua negara atau lebih terhadap suatu obyek yang dipersengketakan. ${ }^{9}$ Obyek yang dipersengketakan pada umumnya dapat berupa masalah kedaulatan negara, masalah perbedaan ideologi dan lain sebagainya. Subyek sengketa internasional adalah negara. Negaralah yang dapat dikategorikan sebagai subyek dalam sengketa internasional. ${ }^{10}$ Meskipun demikian epistemic community tetap melibatkan individu atau badan-badan hukum lain sebagai subyek dalam sengketa internasional. Seperti dalam bukunya, Starke menyatakan bahwa timbulnya sengketa negara-negara pada umumnya dengan munculnya

\footnotetext{
${ }^{9}$ Burhan Tsani, Loc.Cit.

${ }^{10}$ J. G. Starge, Pengantar Hukum Internasional, Edisi Kesepuluh, Penerbit Sinar Grafika, 2008
} 
sengketa antara individu-individu, kecuali akibatnya sengketa pertama dapat lebih berbahaya. $^{11}$

India dengan Pakistan merupakan negara yang mempunyai sejarah konflik cukup panjang. Konflik antara kedua negara tersebut tidak hanya pada konflik perebutan wilayah atas Kashmir semata akan tetapi juga mengarah pada uji coba persenjataan nuklir yang dilakukan oleh kedua negara tersebut. Pada masalah sengketa Kashmir, rakyat Kashmir menginginkan agar diadakannya referendum perihal pembagian wilayah dan juga plebisit yang diajukan oleh PBB. Hal ini menjadi dilema tersendiri bagi India, di satu sisi India menginginkan diadakan referendum tersebut, tapi disisi lain India enggan untuk melaksanakannya, mengacu pada mayoritas penduduk Kashmir beragama Islam yang bertentangan dengan India yang mayoritas beragama Hindu. Perundingan dan diplomasi juga dijalankan oleh kedua belah negara dalam menyelesaikan konflik diantara mereka. Campur tangan Amerika Serikat juga masuk didalamnya, Amerika Serikat mendesak agar India dan Pakistan tidak lagi meluncurkan senjata nuklirnya serta segera mengadakan perundingan perdamaian. Dalam menyelesaikan konflik tersebut, hal pertama yang seharusnya dicapai adalah adanya kesepakatan di antara kedua negara tersebut untuk segera menyelesaikan konflik mereka melalui perundingan damai. ${ }^{12}$

Jalan damai juga turut diupayakan oleh organisasi South Asian Association of Regional Cooperation (SAARC), yang merupakan organisasi internasional regional yang beranggotakan negara-negara Asia Selatan. SAARC ikut membantu menyelesaikan konflik ini sebagai mediator dari India dan Pakistan, dimana kedua negara adalah anggota dari organisasi ini. Akan tetapi dari semua hal yang di upayakan sampai sekarang belum menemukan titik terang dalam penyelesaian konflik wilayah Kashmir. Dengan kata lain selama ini SAARC hanyalah tempat

\footnotetext{
${ }^{11}$ Ibid.

${ }^{12}$ Amal Hamzah. Dunia Sekitar Kita, Pakistan dan India, Penerbit PT. Jambatan, Jakarta, 2002., hal 64
} 
bagi wakil dari India maupun Pakistan untuk bernegosiasi dan berusaha menyelesaikan pertikaian. ${ }^{13}$

Pada tahun 1949 India dan Pakistan mengumumkan genjatan senjata dibawah naungan PBB. Dewan Keamanan PBB melalui United Nation Comission for India and Pakistan (UNCIP) yang anggotanya terdiri dari Amerika Serikat, Belgia, Argentina, Kolombia dan Cekoslowakia melakukan berbagai pertemuan dan kesepakatan mengenai perumusan negosiasi atas genjatan senjata yang dilakukan. Proses-proses tersebut antara lain mengenai batas wilayah genjatan senjata, pengawasan proses genjatan senjata, mengembalikan pengungsi, membebaskan tahanan politik, melaksanakan referendum atas status Kashmir serta penarikan pasukan secara berkesinambungan. ${ }^{14}$

PBB dalam mencari solusi sebagai penyelesaian masalah sengketa Kashmir, lebih mengedepankan cara-cara tanpa menggunakan kekuatan militer untuk menciptakan perdamaian dan keamanan diwilayah sengketa, sesuai dengan konsep liberalisme, dalam hal ini demokrasi lebih di kedepankan. PBB juga menegaskan pelaksanaan jajak pendapat atau referendum merupakan cara yang demokratis dalam menentukan status Kashmir.

Pelaksanaan referendum tidak segera dilakukan dikarenakan keenganan India untuk melaksanakannya. Hal tersebut ini dapat mematahkan teori liberalisme yang menekankan peran suatu rezim Internasional dengan jalan perdamaian merupakan cara yang tidak efektif dalam menyelesaikan sengketa wilayah Kashmir antara India dan Pakistan, dengan munculnya kembali tiga kali perang besar antara India dan Pakistan, menunjukan bahwa konsep realisme yang menggunakan jalan perang dan keamanan lebih efektif terhadap permasalahan Kashmir. Cara-cara anarki yang digunakan India dan Pakistan, dilakukan agar tercipta balance of power. Melihat pada konsep realisme, berlarut-larutnya konflik

\footnotetext{
${ }^{13}$ Ibid. Hal 67

${ }^{14}$ Hamzah, Op.Cit.
} 
Kashmir dikarenakan adanya national interest, faktor keamanan,dan show on force masing-masing negara.

Ada beberapa resolusi yang ditawarkan untuk menyelesaikan masalah di Kashmir, diantaranya adalah; Simla Agreement yang ditandatangani pada tanggal 2 juli 1972, India-Pakistan Non-Attack Agreement yang ditandatangani tanggal 31 desember 1988, dan Agreement Between India And Pakistan On The Prohibition Of Attack Against Nuclear Installations And Facilities (India-Pakistan Non-Attack Agreement) yang diratifikasi pada Desember 1990.

Resolusi yang ditetapkan oleh PBB memang menggunakan cara-cara yang damai dan lebih mengutamakan diplomasi. Akan tetapi usaha yang dilakukan PBB masih belum bisa untuk memperbaiki hubungan kedua negara karena resolusi yang ditetapkan PBB tidak dijalankan sepenuhnya oleh India maupun Pakistan. Bahkan proposal saran yang dibawa oleh utusan-utusan PBB ditolak oleh India dan Pakistan. ${ }^{15}$

\section{Penutup}

Berdasarkan uraian diatas, dapat disimpulkan bahwa status wilayah Kashmir menurut hukum internasional adalah menjadi sengketa, karena India dan Pakistan sama-sama mengklaim Kashmir sebagai bagian dari wilayah mereka. Akan tetapi pada masa lampau penguasa Kashmir yang beragama Hindu, lebih memilih untuk menempatkan Kashmir menjadi bagian dari India, Hal itu membuat India semakin bersemangat untuk mengklaim Kasmir, sehingga Kashmir saat ini terbelah dua, antara Kashmir Pakistan dan Kashmir India. Sengketa wilayah Kashmir terjadi disebabkan oleh benturan atas kepentingan politik kedua negara dan melalui klaim sepihak dari India maupun Pakistan. Dari faktor agama, Pakistan mengklaim bahwa Kashmir yang mayoritas muslim merupakan bagian dari wilayah Pakistan sedangkan India mengklaim di kashmir

\footnotetext{
${ }^{15}$ http://sukmikamardalenachaniago.blogspot.com/2012/08/peran-pbb-dan-saarcdalampenyelesaian. html diakses 17 Januari 2014
} 
terdapat komunitas Hindu yang terintegrasikan dengan India. Begitu juga dari sudut pandang perbatasan, secara teritorial Kashmir berada dalam wilayah India. Akan tetapi sengketa yang terjadi merupakan warisan dari rezim kolonial yang membuat garis batas antar negara menurut kepentingan mereka sendiri tanpa mengindahkan aspek-aspek alamiah seperti suku, ras, kondisi sosial dan budaya.

PBB berkali-kali mengirimkan perwakilannya ke India dan Pakistan untuk mendapatkan jalan atas penyelesaian masalah yang dapat mengakomodasi aspirasi oleh kedua Negara, sebagai bagian untuk menyelesaian sengketa pembatasan wilayah Kashmir melalui hukum internasional. Melalui Dewan Keamanannya PBB menyarankan agar kedua negara segera melaksanakan demiliterisasi di wilayah Kashmir sebagai bagian untuk memastikan proses jajak pendapat berlangsung secara independen. Kegagalan-kegagalan dalam memberikan solusi pada kedua negara yang bersengketa tersebut, tidak membuat PBB mundur untuk menyelesaikan persengketaan Kashmir. Bermacam cara dilakukan kembali untuk menemukan solusi yang benar-benar dapat disepakati oleh India dan Pakistan. Kebijakan yang dikeluarkan PBB lebih mengedepankan diplomasi dan cara-cara damai. 


\section{Referensi}

Amal Hamzah. Dunia Sekitar Kita, Pakistan dan India, Penerbit PT. Jambatan, Jakarta, 2002.

Amsrudin. Refleksi Teori Hubungan Internasional (Dari Tradisional ke Kontenporer), Penerbit Graha Ilmu, Yokyakarta, 2009.

Christian Reus-Smit, 2004. The Politics of International Law, Cambridge University Press..

J. G. Starge, Pengantar Hukum Internasional, Edisi Kesepuluh, Penerbit Sinar Grafika, 2008.

Mohd. Burhan Tsani, Hukum dan Hubungan Internasional, Penerbit Liberty, Yogyakarta,1990.

Safril Djamin. Mengenal Lebih Jauh PBB dan Negara-Negara di Dunia. Klaten:PT.Intan Pariwara

Choudhury, Salah Uddin Shoaib (8 Oktober 2010). "Pakistani rogue policy on Kashmir". Sri Lanka Guardian.

http://sukmikamardalenachaniago.blogspot.com/2012/08/peran-pbb-dan-saarcdalampenyelesaian.html

Icha. Implikasi Konflik Kashmir Terhadap Regional Security Kawasan Asia Selatan.

http://chaegyoung.wordpress.com/2009/10/25/

Abhimata Pradana Setiadi. Sengketa Perbatasan Kashmir: Ditinjau Dari Sudut Hukum Internasional. http://lib.atmajaya.ac.id/default.aspx?tabID=61\&src=k\&id=77382

Uppsala Conflict Data Program Conflict Encyclopedia, Conflict Summary, Conflict name: India: Kashmir, "Roots of Conflict and the emergence of Kashmir Insurgents",

http://www.ucdp.uu.se/gpdatabase/gpcountry.php?id=74\&regionSelect=6Central_and_Southern_Asia\# 